\title{
UNA FALLIDA PRIVATIZACIÓN DEL AGUA EN BOLIVIA: el estado, la corrupción y el efecto neoliberal
}

\author{
Camilo Sanz Galindo
}

INVESTIGADOR INDEPENDIENTE

camsaga@yahoo.com

\begin{abstract}
Resumen
[ N 1999, EL GOBIERNO BOLIVIANO VENDIÓ LA EMPRESA DE AGUA DE COCHABAMBA A UN [ grupo de inversionistas nacionales y extranjeros. Sólo tres meses después se produjo un levantamiento popular sin precedentes en respuesta a los dramáticos incrementos en las tarifas del servicio, las relaciones íntimas, y subterráneas, entre el estado y el nuevo consorcio, y las formas de riqueza que están sujetas a las apropiaciones del estado y las firmas privadas. Este artículo analiza la intersección del estado, el mercado y la corrupción bajo las nuevas contradicciones de jurisdicción producidas bajo las condiciones neoliberales. Aborda al neoliberalismo como un proceso que borra la frontera entre el estado y el mercado y genera un simulacro de orden social, en el cual la corrupción y el robo no van en contra del estado, sino que, por el contrario, hacen parte del mismo.
\end{abstract}

PALABRAS ClAVE: estado, mercado, corrupción, neoliberalismo, privatización, globalización, agua, Bolivia.

\section{Abstract}

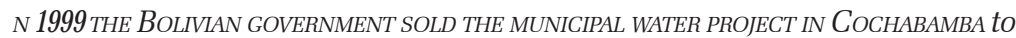
a consortium of local and foreign investors. Only three months after the contractual agreement was signed, an unprecedented popular uprising took place. People mobilized against the dramatic increment in water rates, the intimate (and underground) relations between the state and the corporations, and the forms of wealth that were appropriated by state and private enterprises'. This essay studies the intersections between the state, the market, and corruption under the new contradictions of jurisdiction opened up under neoliberal conditions. I propose that Neoliberalism should be seen as a process that blurs the frontier between the state and the market, generating a simulacra of social order in which corruption and graft do not challenge the state, but on the contrary, make part of it.

KEY WORDS: State, market, corruption, neoliberalism, privatization, globalization, water, Bolivia. 


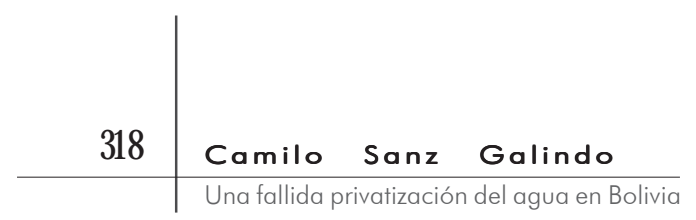

\section{INTRODUCCIÓN *}

A EXPANSIÓN DEL NEOLIBERALISMO Y LA CREACIÓN DE LOS MERCADOS globales de productos básicos han sido dirigidas por la capaci- dad que tiene el mercado para controlar no sólo la fuerza laboral barata, los mercados y la tecnología, sino también la naturaleza. "La tierra, los recursos subterráneos, el aire y la luz",

* Este artículo es una versión de mi tesis de maestría de la Universidad de Chicago, agosto de 2006. según Lefebvre, "son todos parte de las fuerzas de producción y, así mismo, productos de esas fuerzas" (1991: 347). Como parte de dicha tendencia, el agua ha dejado de ser un servicio y un bien público, sujeto al control y la vigilancia gubernamental, y se ha convertido en un artículo manejado, cada vez más, de acuerdo con principios económicos y derechos de propiedad. En este proceso, advierten Comaroff y Comaroff (n. d), los medios y los fines del estado democrático liberal son reflejados, desviados y luego diseminados en los oscuros alcances del sector privado, en ocasiones de maneras inimaginables hasta por los más audaces capitalistas, y otras veces sin que parezca alterarse el orden establecido de las cosas.

Hasta 1990, menos de cincuenta y un millones de personas recibían el agua potable por intermedio de empresas privadas, y la mayoría de esos consumidores se encontraban en Europa y Estados Unidos. En esa misma época, el estado en países en desarrollo seguía manteniéndose firme en su papel de proveedor de agua potable, y subsidiada, para toda su población. Sólo diez años después, de acuerdo con Michael Goldman, "más de 460 millones de personas se vuelven dependientes de las grandes transnacionales que prestan el servicio de agua potable" (2005 232). Compañías tales como Vivendi, Veolia, Suez y Bechtel, entre otras, han venido trabajado conjuntamente con el Banco Mundial y otras instituciones financieras, con el fin de hacer presencia en todos los continentes e influir sobre los gobiernos locales para que privaticen el agua de sus ciudades y se vinculen al debate mundial sobre la escasez del recurso. En dicho proceso, la democratización y la liberalización de los mercados en países como Bolivia, y su intersección con la administración de los recursos naturales, producen el reordenamiento de las distinciones entre el mercado y el estado, así como de lo público y lo privado. En otras palabras, en la medida en que la pri- 


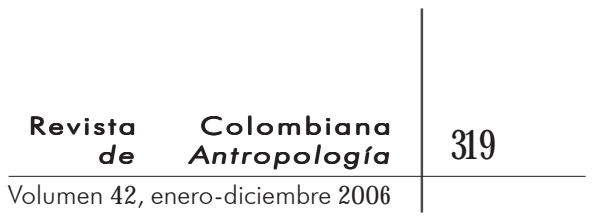

vatización crea nuevas formas de propiedad e intersticios de regulación, auspicia simultáneamente nuevas formas de corrupción y escenarios de producción de riqueza.

Con el fin de explorar este fenómeno, me centraré en el caso de la histórica guerra del agua en Cochabamba (Bolivia), conocido en el mundo como un levantamiento popular sin precedentes en contra de las fórmulas más extremas del dictum neoliberal: la privatización del agua. Así las cosas, en septiembre de 1998, el Fondo Monetario Internacional (FMI) aprobó un préstamo considerable para combatir la pobreza y estimular el crecimiento económico en Bolivia. Sin embargo, para que dicho préstamo se desembolsara el gobierno boliviano estaba obligado a vender las empresas públicas restantes, incluyendo las refinerías nacionales de petróleo y Semapa, la empresa municipal de agua cochabambina. Un año después, y luego de negociaciones a puerta cerrada, el gobierno definió los términos del contrato y traspasó los derechos al nuevo consorcio, Aguas del Tunari, conformado por una minoría de inversionistas locales y una mayoría extranjera. En marzo de 2000 se materializó una revuelta popular que demandaba la expulsión de la nueva compañía. Los manifestantes expresaban su desacuerdo con la percepción estatal del agua como riqueza, las íntimas y oscuras relaciones entre el estado y las corporaciones, y las formas de riqueza sujetas a sus actos de apropiación indiscriminados. Dicho esto, este escrito es un esfuerzo por comprender los desacuerdos contemporáneos sobre la privatización del agua en Bolivia y sus efectos mundiales, la apropiación de los medios de supervivencia y la reimaginación de los marcos legales que afectan las relaciones de la población con el estado.

El caso del agua inaugura un momento en la historia en el que la gente experimenta la indeterminación de las bases de poder y los marcadores de certeza o, en otras palabras, el desvanecimiento progresivo de las divisiones que separan al estado del mercado, la legalidad de la ilegalidad, lo público de lo privado. En este sentido, me propongo demostrar que la fase actual del capitalismo se encuentra precisamente instituida y sostenida por la disolución de dichos marcadores y, como consecuencia, intentaré problematizar los límites entre el estado y su "otro", específicamente el "mercado", y entre el ámbito público y privado. De hecho, tal y como nos advierte Mitchell, "la frontera entre el estado y el mercado representa una distinción aún mas elusiva que aquella existente entre el estado y la sociedad" (1999. 170). Tal y como 


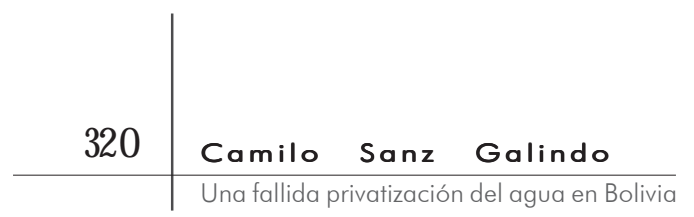

pretendo demostrar, la relación estado/mercado es muy ambigua, por lo general son dominios tanto recíprocos y cómplices como competitivos y antagónicos.

Como parte de esta discusión, pretendo explorar la manera en que el estado se convierte en mediador entre la población y las corporaciones transnacionales, que alguna vez fueron vistas por académicos como Hardt y Negri (2000) como entidades fantasma, invisibles para el común de la población. Es decir, a medida que el estado se convierte en garante de las condiciones propicias para la inversión extranjera (Krasner, n. d), es identificado simultáneamente como blanco innegable del descontento y revuelta popular en contra de los abusos cometidos por firmas comerciales. Ilustraré este fenómeno usando el análisis de Claude Lefort sobre el centro de poder en el mundo premoderno: "El Príncipe era el mediador entre los mortales y los dioses o, a medida en que la actividad política era secularizada y laicizada, entre los mortales y las agencias trascendentales representadas por la justicia y la razón soberana” (1988: D). En otras palabras, el príncipe era el representante directo de lo supremo en la tierra y quien establecía una vía de comunicación entre lo terrenal y lo divino. Dicho esto, es posible extrapolar este ejemplo al caso del agua, en el que por medio del estado la gente logra hacer visible lo invisible, materializar lo etéreo. Es precisamente mediante las prácticas estatales relativas a la economía, la corrupción y el reordenamiento de los espacios públicos y privados que una transnacional es imaginada.

\section{El efecto neoliberal}

D ERMÍtanme ILUSTRAR DE MANERA MUy BREVE, CASI IRRESPONSABle, las características propias del neoliberalismo de acuerdo a como fueron pensadas por sus creadores. Después introduciré mi propuesta para repensar a esta forma de capitalismo tardío y trazaré las bases teóricas que sustentarán la discusión central del artículo. Por el momento, entonces, comienzo haciendo referencia al neoliberalismo como un conglomerado de prácticas y doctrinas económicas concebidas a mediados de la década de 1970, que asegura que el bienestar del ser humano se puede alcanzar no mediante el intervencionismo keynesiano de épocas pasadas, sino por medio de la liberalización de mercados en un marco institu- 


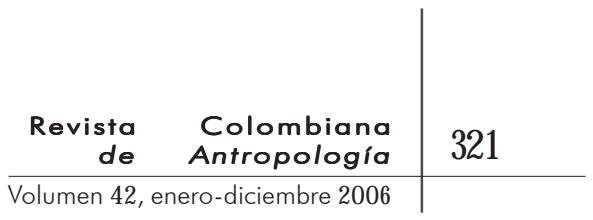

cional caracterizado por sólidos derechos de propiedad, la flexibilización de la normativa comercial, el desmantelamiento progresivo del estado y su consecuente separación del mercado.

Según los defensores del neoliberalismo, esta separación tajante entre el estado y el mercado tendría su razón de ser en la imposibilidad del estado para manejar, comprender y descifrar las señales del mercado, reducir los precios y aumentar la eficiencia, pero más importante aún, de evitar que grupos poderosos distorsionen y re-canalicen las intervenciones estatales -particularmente en las democracias- para sus propios beneficios. Bajo la doctrina neoliberal se espera que la economía logre un mayor desempeño en la medida en que la gente pueda elegir libremente y sin restricción gubernamental. No en vano los padres del neoliberalismo concibieron este conjunto de prácticas como intrínsecamente relacionadas con la democracia, tomando los ideales políticos de dignidad humana y libertad individual como valores centrales de la civilización. En esta lógica, organismos multilaterales como el Banco Mundial y el FMI se convierten en centros de propagación de estas prácticas y las imponen como condiciones para efectuar préstamos a países pobres, re-negociar sus deudas y, supuestamente, darle un impulso a sus ya golpeadas economías.

En la práctica, sin embargo, la situación actual de países como Bolivia no parece encajar en esa lógica. Debe reconocerse el débil desempeño económico de la región, la tendencia creciente hacia las prácticas autoritarias en algunos países y los niveles alarmantes de pobreza, desigualdad y corrupción. Tal y como demostraré, el libertinaje del mercado y la consecuente flexibilización de la normativa comercial nos transportan a un escenario del "mundo al revés”, en el que se establece una relación de complicidad entre el estado y el mercado y se desvanecen progresivamente sus fronteras. Tal y como sugieren Comaroff y Comaroff (n. d), a medida que el estado comienza a contratar la prestación de servicios con firmas privadas -salud, electricidad, agua potable, etcétera- y el cumplimiento de sus responsabilidades -seguridad y protección para los ciudadanos-, y una vez que las organizaciones privadas remedan al estado, el orden social asume la apariencia de un "cuarto de espejos" regido por una intensa y desconcertante reflexión de imágenes. Lo oficial y lo formal se convierten en falsificación, la corrupción y el robo en la realidad, el contrabando en método válido de comercio, siendo el mismo estado el que 


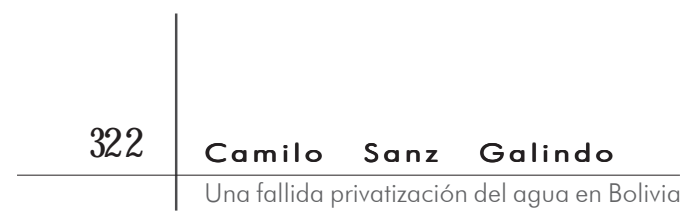

se confunde, y hasta se fusiona, con estos ámbitos y prácticas que se suponían proscritos.

Desde los análisis inspirados por Weber, la mayoría de los esfuerzos han buscado establecer la independencia del estado de su contexto socioeconómico y en privilegiar el rol intencional de los agentes políticos en los ámbitos nacional e internacional. Desde el marxismo el debate se ha centrado en las maneras de abordar los nexos entre el estado y el capitalismo, sobre la presunción de que los estados se constituyen y organizan en respuesta a su rol de reproductores de las relaciones capitalistas. Así las cosas, mientras los neoweberianos tienden a establecer una separación tajante entre el estado y el mercado, así como a valorar los diferentes grados de las "capacidades estatales” (Skocpol, 1985), los marxistas, por su parte, generalmente asumen la existencia de una conexión estructural entre estos dominios y se interesan en explorar sus implicaciones para la forma y la autonomía relativa del estado (Poulantzas, 1978).

En este orden binario parecieran existir, por un lado, individuos y sus actividades, y, por otro, una estructura inerte que de alguna manera se aparta de los individuos, los precede, los contiene, dándoles un marco a sus vidas. Así pues, en este mundo en que vivimos, dice Coronil (1997), la realidad parece tomar una forma bidimensional de individuos frente a aparatos, mercado frente a estado. Sin embargo, esta separación persistente, especialmente entre estado/mercado, no permite evidenciar la forma en que las prácticas neoliberales generan una íntima dependencia entre dichos dominios, ni mucho menos la reconfiguración de sus límites (MacKinnon, 1989, Mitchell, 1991, 1999, Coronil, 1997). Según Mitchell (1999), una propuesta alternativa debería contemplar seriamente el carácter volátil de dicha frontera, no como un problema de precisión conceptual, sino como una pista sobre la naturaleza del fenómeno. En vez de buscar una definición que establezca claramente esa división, es necesario examinar los procesos legales y económicos mediante los cuales se produce la incierta pero poderosa distinción. En respuesta a esta necesidad, este artículo invita a pensar en una visión alternativa del neoliberalismo, que dé cuenta de las fronteras porosas y móviles dentro del estado/mercado.

Con base en el legado de Deleuze y Guattari (1987), pretendo demostrar que, en la medida en que el estado ocupa el mercado, este último se extiende hacia el primero, y como "rizomas" que 


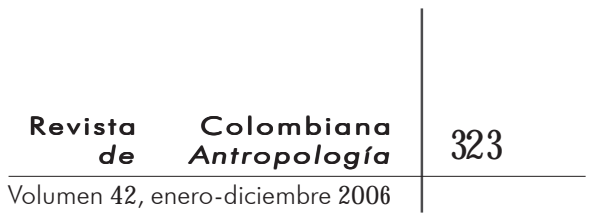

son, comparten una unidad fundamental en la diferencia. Entonces, de manera contraria al entendimiento del neoliberalismo como una separación radical mercado/estado, propongo entenderlo como una dialéctica que problematiza la dicotomía inicial, redefinir los límites de dichos dominios, las prerrogativas del poder público y la codificación de los derechos, los privilegios y las iniquidades tolerables en una sociedad.

Sin embargo, es necesario advertir que esta división resulta ser más compleja de lo que aparenta; en este sentido, el estado no debería ser considerado necesariamente como el orden "público" de los intereses generales de lo real e imaginado, ni sería aconsejable tampoco entender al "mercado" únicamente como el dominio de los intereses privados. De hecho, tal y como discutiré más adelante, existen divisiones internas dentro del estado/mercado que presumiblemente no responden a su usual apariencia estructural. Apoyándome en Mitchell (1991), buscaré demostrar que la frontera estado/mercado nunca marca un exterior real. Esta frontera no es el perímetro de una entidad intrínseca, que pueda ser pensada como un objeto o actor libre e independiente. Por el contrario, es una línea demarcada internamente, dentro de la red de mecanismos institucionales y marcos legales que, presumiblemente, se proyectan en lo público y privado. El hecho de que la frontera del estado nunca marque un exterior real puede dar luces sobre su misma naturaleza esquiva e inestable, a la cual Bhattacharjee (1990) se refiere como "ahora-lo ves-ahora-no-lo-ves".

Pero esto no significa que la línea sea ilusoria; por el contrario, tal y como el caso del agua parece indicar, producir y mantener la distinción estado/mercado es, en sí, un mecanismo que genera recursos de poder. El hecho de que Aguas del Tunari pueda yacer fuera del sistema político formal es esencial para su fortaleza como parte de un orden político mayor. Tomemos el ejemplo de las empresas conjuntas de agua o de los acuerdos comerciales en los que, en ocasiones, el estado puede ser constituido como inversionista líder, mientras que las firmas privadas reciben la mayoría de los beneficios al hacer el trabajo infraestructural y contractual (Goldman, 2005). En este ejemplo, la relación entre las grandes transnacionales del agua, empresas mixtas o semipúblicas y organismos multilaterales, representa cadenas entrelazadas de poder y regulación del agua. Ninguna división simple podría separar esta cadena en público y privado o en estado y mercado. Simultáneamente, las empresas son constituidas y presentadas como 


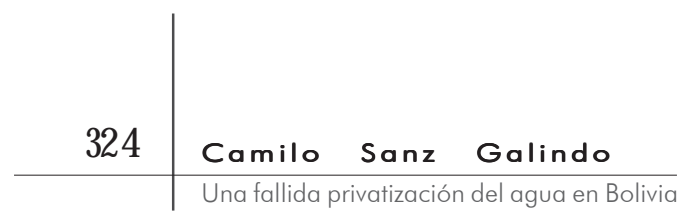

instituciones privadas claramente diferenciadas del estado. La apariencia de que el estado y el mercado son cosas separadas es parte de la manera en que se mantiene un orden económico, o del agua.

Se podrían explorar muchos otros ejemplos (Krasner, 1978), aun cuando por ahora basta con reconocer que, en cada caso, la división estado/mercado no es una simple frontera entre dos objetos libres e independientes, sino una distinción interna y compleja de estos ámbitos de la práctica. Por tanto, cabría preguntarnos ¿cómo se genera el efecto que hace que ciertos aspectos de lo que ocurre pertenezcan al mercado, mientras otros se distancien como el estado?

\section{LA GUERRA DEL AGUA EN BOLIVIA}

N MARZO DE 2000, MILES DE MANIFESTANTES PACEÑOS Y COCHA- bambinos abarrotaron la plaza Murillo, punto neurálgico de la ciudad de La Paz, llevando consigo palos, rocas y pañuelos para bloquear el inminente gas lacrimógeno. Los manifestantes gritaban arengas en contra del gobierno nacional, la privatización del agua en Cochabamba y su venta a manos de Aguas del Tunari. De acuerdo con Óscar Olivera, el líder del movimiento: "La gente expresaba su profundo descontento frente a la inminente transformación del agua en un bien exclusivo y privado, algo que destruye el derecho a la libertad y dignidad” (2004: 17). En las pancartas de la manifestación se leían diferentes consignas: "Viva la unidad del pueblo en contra de los sirvientes del neoliberalismo", "En contra del gobierno vende-patrias", y "Muere gobierno corrupto y asesino" (Albro, 2005). Entretanto, los reportes de la radio y la televisión especulaban el día entero si el presidente declararía o no la ley marcial, mientras numerosas unidades del ejército llegaban al aeropuerto de la ciudad. Dentro del Palacio Quemado, el presidente Hugo Banzer (1997-2001) $\mathrm{y}$ varios de sus ministros se encontraban buscando desesperadamente una salida al problema, y calmar los ánimos de la gente. Pero, antes que todo, el gobierno debía hacer concesiones a los centenares de manifestantes que se encontraban a pocos metros del palacio presidencial. Esta vez, la gente decía, "ninguno de nosotros va a dejar la plaza Murillo hasta que el gobierno haya considerado nuestras demandas y expulsado del país a 


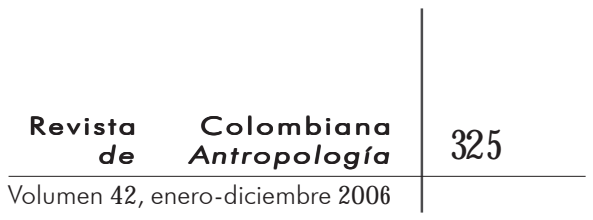

Aguas del Tunari; modificado las nuevas tarifas del agua y abrogado la nueva ley 2026 que prohíbe realizar prácticas tradicionales con el agua” (Olivera, 2004: 5). La gente preguntaba, ¿cómo pueden las mafias gubernamentales y las corporaciones adueñarse de un derecho humano como el agua potable? (Postero, 2005). Después de ocho días de intensa protesta, el gobierno cedió: revocó el contrato y expulsó finalmente a Aguas del Tunari, concediendo el control total de Semapa a un directorio regional.

A pesar del hecho de que el gobierno corrupto le da autoridad a criminales vestidos de policías para aplastarnos, nuestros palos y piedras vencieron a los cobardes, mediocres y corruptos oficiales del gobierno. La solidaridad triunfó sobre la conspiración del gobierno y logramos desarticular su cínica defensa a favor de sus oscuros negocios (Olivera, 2004: 36).

Después de veinte años de innumerables movilizaciones populares en contra del neoliberalismo, la guerra del agua se convirtió en la primera victoria en contra de estas políticas, sentando un precedente indiscutible para otros casos similares alrededor del mundo. A diferencia de otros tipos de privatización, el caso del agua afecta una de las fibras más sensibles de la sociedad, aquella ligada a la vida y la muerte, la construcción del ser, los derechos humanos y la criminalidad del estado. De acuerdo con el director del Centro Salvadoreño para Tecnología Apropiada (Salvadoran Center for Appropriate Technology), Ricardo Navarro, "el agua se convertirá en un recurso estratégico, y gran parte de las futuras acciones políticas y militares serán determinadas por la oferta de agua para los habitantes más poderosos del planeta". Luego, agrega Navarro, "lo que debe ser una fuente de vida terminará por convertirse en una fuente de discrepancia y violencia” (Dalton, 1995).

El caso boliviano es apenas uno de tantos ejemplos, quizás el más violento, que refleja la realidad problemática alrededor del mundo, en la cual los gobiernos neoliberales enfrentan crecientes protestas públicas. La guerra del agua, como una revuelta civil en contra de la privatización y mercantilización de la vida, se convirtió en "el ejemplo por mostrar de lo que sucede cuando un país pobre es dejado a manos de los economistas en planificación global e inmerso en una corrupción política profunda" (Shultz, 2000). En el caso de las privatizaciones, muchos de los 


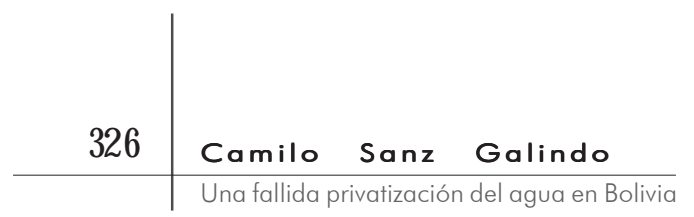

nuevos contratos con las corporaciones transnacionales han sido, y actualmente son, ampliamente rechazados. La municipalidad de Cuzco (Perú) decidió terminar el contrato con la Corporación Suez y continuar manejando y distribuyendo el agua potable sobre una base pública. En febrero de 2003, Bogotá decidió romper con la tendencia a la privatización del agua, rechazó dineros del Banco Mundial y transformó su utilidad pública en una de las más exitosas de Colombia. En Grennoble (Francia), después de muchos años bajo el régimen de Lyonaise de l'eau, el gobierno local decidió transferir la compañía del agua a la esfera pública (Goldman, 2005). Por si fuera poco, en septiembre y octubre de 2004, Holanda y Uruguay declararon la privatización del agua como práctica ilegal. En ambos casos, de acuerdo con David Hall, director de la Unidad internacional de investigación de servicios públicos de la Universidad de Greenwich, "las nuevas leyes proscriben no sólo la venta de los sistemas de agua, sino también el traspaso de la operación de distribución de agua a manos privadas" (2004: 2).

Es evidente que los cuestionamientos sobre la efectividad de estas políticas económicas se encuentran girando con gran intensidad alrededor del mundo. Actualmente, la inversión del sector privado enfrenta grandes obstáculos; las compañías multinacionales no logran recuperar las inversiones iniciales, y los procesos de privatización del agua y energía eléctrica han probado ser lo suficientemente impopulares. Por si no fuera poco, se tiende a asociar al mercado con la destrucción, aun cuando no precisamente con la destrucción creadora. Por lo general, cuando se firman los contratos de privatización del agua las tarifas se duplican y triplican, convirtiendo este recurso en un lujo que pocas familias pobres pueden costear y en una excusa para que empresas como Aguas del Tunari corten el servicio y el derecho a la vida. En 2002, por ejemplo, una zona pobre de Johannesburgo (Sudáfrica) se encontraba al borde de un brote de cólera como resultado de los cortes de agua y electricidad (Goldman, 2005). Pero aparte del incremento injustificado en las tarifas de los servicios privatizados, los niveles de corrupción se disparan dramáticamente (Hall, 2004). Los estímulos propuestos por el Banco Mundial para privatizar los servicios públicos y la infraestructura han multiplicado la escala potencial de este negocio; se incentiva el ofrecimiento de sobornos a los funcionarios públicos por parte de las transnacionales para 


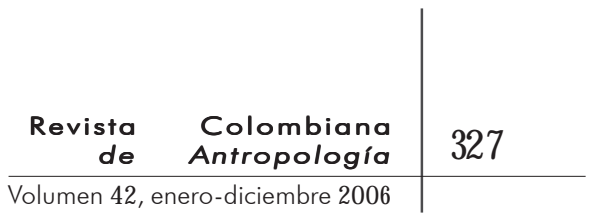

asegurar contratos y concesiones. Inevitablemente, dichos negocios suponen la creación de monopolios a largo plazo, en los que se presta un servicio esencial pero con potencial considerable de ganancia. Sin duda, los obstinados esfuerzos por privatizar empresas públicas aún se mantienen, mientras que los gobiernos alrededor del mundo, en su búsqueda por la aceptación popular, hacen despliegue de su lógica discursiva y desarrollan tortuosos eufemismos tales como "capitalización”, para el caso boliviano, "reforma de propiedad" (China), "desinversión” (India), “desincorporación” (México), "transformación para la gente” (Sri Lanka) y "proceso de equidad” (Vietnam).

A pesar de los esfuerzos estatales evidentes, los consumidores alrededor del mundo siguen preguntándose ¿cómo puede estar determinado y controlado el derecho a la vida por un puñado de corporaciones? Para muchos, es cuestión de ceder el derecho a vivir y el plan providencial a morir a los caprichos de una lógica más eficiente y rentable. Esta es, precisamente, la astuta mercantilización de los derechos inalienables y de las condiciones vulnerables ampliamente asociadas con los habitantes de los países en desarrollo: especies en peligro de extinción, artefactos antiguos, trabajadores sexuales y emigrantes indocumentados, niños y órganos (Comaroff y Comaroff, n. d). Estas instancias nos recuerdan, si es que fuese necesario, la manera en que la política y el crimen, la actividad legítima e ilegítima, se redefinen mutuamente sin cesar.

\section{El neOliberalismo en Bolivia: UN VISTAZO}

D ESDE LA REVOlución DE 1952 hasta mediados de 1980, Bolivia atravesó por un periodo de dictaduras militares y sucesivos golpes y contra-golpes de estado, persecuciones políticas, tráfico de drogas y un desangre progresivo de la débil economía nacional. A principios de la década de 1980, el país se encontraba sumido en una de las crisis económicas más profundas de la historia mundial del siglo veinte. En 1985 el gobierno nacional introdujo reformas neoliberales para detener la inflación galopante y convertir a Bolivia en un país competitivo en el mercado mundial. Las reformas impuestas por las principales instituciones 


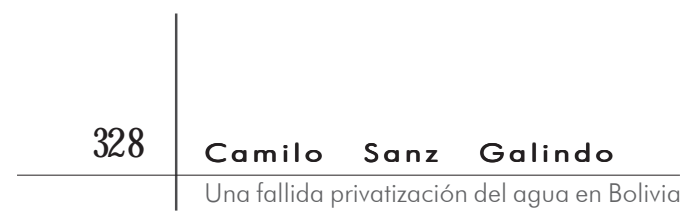

financieras, FMI y Banco Mundial, por lo general contenían un componente financiero; específicamente, el restablecimiento de los presupuestos nacionales, la reforma de los sistemas sociales, el alivio de la deuda y la reestructuración y privatización de los sistemas bancarios (Gill, 2000). Estas reformas incluyeron también un aspecto comercial, que involucró la liberalización del comercio doméstico y extranjero, así como el cierre de ciertas asociaciones de consumidores y de cuerpos reguladores del comercio. Un tercer aspecto en la agenda fue la reforma económica, que incluyó la reducción de los procedimientos que gobiernan la producción, las inversiones y la privatización de empresas estatales (Hibou, 1999, Harvey, 2005), tales como la energía eléctrica, las telecomunicaciones, el transporte, la sanidad y el agua. El objetivo de estos ajustes estructurales era restablecer la salud de las finanzas públicas tan rápido como fuese posible y, luego, paso a paso, darle un nuevo comienzo a una de las economías más pobres. La reducción de la corrupción, la arbitrariedad en asuntos administrativos y la absorción de mercados y sectores informales en el sector económico formal fueron vistas, con razón suficiente, como objetivos indispensables para el buen funcionamiento de las economías de mercado. En Bolivia estas reformas fueron una de las iniciativas más draconianas implantadas en cualquier país latinoamericano y representaron mucho más que un ajuste. De acuerdo con Leslie Gill (2000), expusieron a los más pobres y a sectores de la clase media a severas privaciones.

Para nombrar algunos de los casos, a principios de la década de 1980 los primeros programas de ajuste estructural en Bolivia fueron implementados en el sector minero, dejando sin trabajo a miles de familias que vivían del estaño (Nash, 1979, Postero, 2005). De hecho, como comenta Gill (2000), la minería era el sector más crítico de las políticas del FMI, y durante muchos años desafió al poder del estado. Más notable aún fue una forma particular de privatización llamada capitalización, por medio de la cual el gobierno vendió a compañías extranjeras las acciones de cinco de las más grandes empresas públicas, incluyendo Yacimientos Petrolíferos Fiscales Bolivianos (YPFB), la petrolera estatal. Como en la mayoría de países latinoamericanos, Bolivia posee los derechos sobre todos los recursos naturales subterráneos. Sin embargo, la capitalización de YFPB modificó esto, en parte porque le concedía a los socios extranjeros derechos sobre la mitad de las ganancias de la compañía (Postero, 2005). En 1997, al término de 


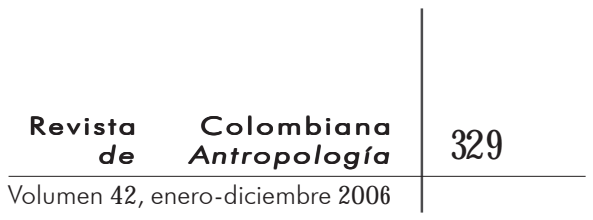

su primer mandato presidencial, el presidente Gonzalo Sánchez de Lozada (1993 1997) decidió llevar esta privatización aún más lejos, al expedir un decreto que le permitiría a las transnacionales explorar y explotar campos de gas natural, bajo concesión cedida por el gobierno, para luego exportar el recurso a través de puertos chilenos. En los setenta y ocho contratos firmados hasta ese momento, a las transnacionales se les garantizaba el derecho de propiedad sobre el gas natural "a boca de pozo", es decir que "mientras que el gas pertenecía a los bolivianos al encontrarse bajo tierra, éste pasaba automáticamente a ser propiedad exclusiva de las corporaciones al ser bombeado y vendido" (Petras, 2004: 3). Contratos celebrados con estas compañías fijaron las ganancias bolivianas en $18 \%$ para el caso de nuevas reservas descubiertas. Bajo el plan propuesto para exportar gas a través de Chile, las corporaciones hubieran tenido que vender el gas a un precio muy bajo a las compañías encargadas de filtrarlo y transportarlo. Por otra parte, los consumidores bolivianos deberían haber pagado altos precios por su uso doméstico (Postero, 2005). Mientras que dicho acuerdo comercial habría tenido sentido desde el punto de vista del capitalista, quien vende un bien en un mercado internacional inestable, desde el punto de vista de los más pobres en Bolivia habría significado la reiteración de la fórmula según la cual los ricos se hacen más ricos.

A finales de septiembre de 1998, el sindicato nacional de trabajadores, la Central Obrera Boliviana (COB), convocó a una huelga general indefinida para hacer frente a las políticas económicas del gobierno. Sus integrantes pedían que el gobierno re-nacionalizara el sector de los hidrocarburos que había sido privatizado, y canalizara recursos como el gas natural para impulsar el desarrollo de la industria nacional (Cherian, 2003). Los mineros y los profesores fueron los primeros sectores en responder. Lentamente, otros más fueron adhiriéndose: los estudiantes empezaron a marchar y los campesinos de la región de Yungas bloquearon las carreteras que conectan con la ciudad de La Paz. En Cochabamba, los sindicatos se unieron, llenando las calles con manifestantes que cargaban consignas como: " $i E l$ gas es nuestro!”, y “iSí a la industrialización!”. Para muchos bolivianos, el plan del gas estaba dilapidando los recursos de la nación, y no estaban dispuestos a ver repetido el patrón de venta de materia prima a los países más desarrollados. 


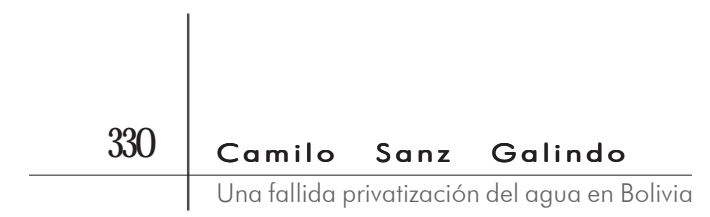

Aun cuando los casos mencionados, particularmente el del gas, generaron desacuerdo popular, sin duda ninguno implicó mercantilizar ni regular el derecho a la vida de poblaciones pobres. En consecuencia, la movilización popular cobró vida y se constituyó en una de las más avasalladoras y exitosas que hayan ocurrido en Bolivia desde la revolución de 1952.

\section{LA GOBERNABILIDAD DEL AGUA Y EL EFECTO NEOLIBERAL}

\section{Fabricando la ley}

F n Un COMIENZO, LA MUNICIPALIDAD DE COCHABAMbA ERA LA ENCARgada de tratar las aguas lluvias y distribuirlas a su población desde una represa cercana. Mientras que las zonas céntricas contaban con el servicio de acueducto, las periféricas debían atenerse a la distribución semanal del recurso por medio de camiones cisterna. En zonas aún más alejadas, la gente empleaba prácticas tradicionales y de muy bajo costo, tales como casas cooperativas y pozos cavados en los mismos hogares. Inesperadamente, los tres sectores mencionados se vieron drásticamente afectados por la venta de Semapa. No solo las crecientes tarifas eran un problema, sino también el hecho de que la ley 2026 estipulaba que Aguas del Tunari debía ser el único proveedor reconocido dentro del territorio cubierto por la privatización. La gente era consciente de que los derechos y libertades individuales estaban siendo modificados; lo que usualmente era entendido como el espacio privado del individuo y sus derechos estaba siendo reformulado bajo lógicas comerciales. Inclusive la fracción de la población que residía en las márgenes de la región y que carecía del servicio de acueducto y camiones cisterna debió enfrentar también los efectos de la privatización; para la nueva ley del agua, los pozos cavados dentro de las mismas viviendas eran ilegales y Aguas del Tunari se encontraba en el legítimo derecho de denunciar dichas "irregularidades" ante los organismos de seguridad del estado. Por si fuera poco, la ley prohibía el uso de tanques para la recolección de aguas lluvias. "La lluvia también había sido privatizada. Para recolectar aguas lluvias, la gente estaba obligada, por la ley 2026, a pedir permiso al superintendente del agua" (Shultz, 2000). 


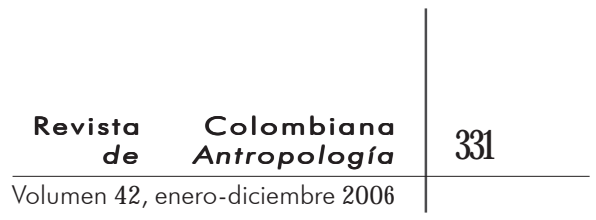

Inexplicablemente, para muchos bolivianos la nueva compañía parecía haber obtenido gran maniobrabilidad e influencia, no sólo sobre las decisiones estatales, sino sobre el espacio privado de la población y su derecho a la vida. Cuando los medios de comunicación preguntaban acerca de los detalles del acuerdo, los funcionarios solían responder: "Todo fue cuidadosamente sujeto a la ley boliviana, a la constitución de nuestro país” (Shultz, 2000). Pero el gobierno, viéndose cada vez más arrinconado por la ola de críticas y protestas populares, declaró públicamente que no contaba con las herramientas jurídicas para cambiar el rumbo de los hechos: el contrato firmado contaba con una cláusula que impedía cualquier intromisión del mismo gobierno en la actividad comercial de la empresa y, ni siquiera, "perjudicar" sus intereses. Además, el contrato firmado sustituía cualquier otro acuerdo o ley anterior. En otras palabras, el gobierno se declaraba impedido por los mismos marcos legales que alguna vez había promulgado y sobre los que se fundamenta toda actividad comercial en territorio boliviano.

Al parecer, dos fenómenos simultáneos ocurrieron: por un lado, Aguas del Tunari hacía lo que las condiciones locales le permitían, es decir, explotar inteligentemente los vacíos en la legislación comercial, de recursos naturales y el código penal; por otro, el mismo gobierno, en su afán por cerrar el acuerdo comercial y anular cualquier aspiración en contra de la venta de Semapa, suspendió y transgredió las mismas leyes que alguna vez promulgó y defendió. Entonces, estamos hablando de la mecánica básica que opera en el estado de excepción (Agamben, 2005), cuando el mismo estado suspende la ley y, en consecuencia, obtiene el poder y la "legitimidad" para emprender cruzadas en contra de las grandes amenazas que afecten su integridad. En términos de Agamben (2005), Derrida (2002) y Benjamin (1978), el estado crea un espacio desprovisto de ley, en el que se desactivan o reformulan todas las determinaciones legales, y, sobre todo, las distinciones entre lo público y lo privado. Es indudable que las corporaciones transnacionales actúan de acuerdo con la flexibilidad de los marcos legales locales. Dentro del proceso de de-regulación, cualquier porosidad o ambigüedad en la ley puede ser utilizada para beneficio de la lógica comercial. En este sentido, Aguas del Tunari obtuvo la autoridad necesaria para entrar a los hogares cochabambinos e imponer un nuevo código de propiedad y derechos humanos. 


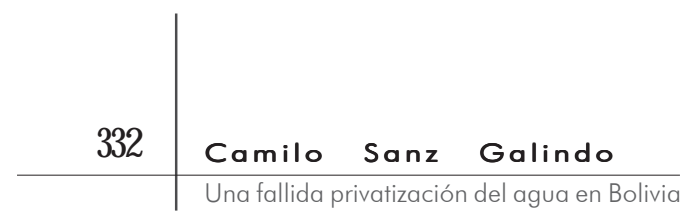

De hecho, las negociaciones del contrato de privatización debilitaron la línea divisoria entre lo informal y lo ilegal, regulación e irregularidad, orden y caos organizado. En este sentido, Comaroff y Comaroff (n. d) comentan que existen grandes rentabilidades que se empeñan por mantener zonas de ambigüedad entre la presencia y la ausencia de la ley, aquellas ganancias generadas a partir del control de la incertidumbre, el terror, hasta la vida misma; de privatizar contratos públicos y recursos naturales; de unas prácticas policivas discrecionales y de lavado de activos; de amasar riqueza o, en otras palabras, explotar hábilmente las nuevas contradicciones de jurisdicción abiertas bajo las condiciones neoliberales. En esta lógica se evidencia un conjunto de prácticas y técnicas estatales que escapan al orden y la sistematización jurídica. En su mero discurso, como afirma Poulantzas, "cada sistema jurídico permite que el estado sea indiferente a sus propias leyes y normas, y logre modificarlas en el transcurrir del juego que este mismo organiza" (1978: 84). En el caso del "estado concesionario" (Mbembe, 2001), los marcos legales locales y el lenguaje de los contratos son re-definidos imprudentemente para satisfacer los criterios de la inversión internacional y las especificidades técnicas requeridas por las corporaciones (Goldman, 2005).

En ese entonces, el descontento popular seguía intensificándose, mientras que la población se daba por vencida en su búsqueda de herramientas legales para defenderse. Para ella el camino no era otro distinto al de mantenerse firme en sus demandas y en la movilización popular. Los manifestantes continuaban exigiendo que la distribución del agua se diseñase no desde la lógica mercantilista ni la búsqueda de ganancias, sino desde una perspectiva social y de bien público que subordinase los aspectos comerciales -criterio de inversión, planes de expansión y precios- al interés común. Como tal, los ciudadanos comenzaban paulatinamente a ser partícipes de sus relaciones económicas con el estado; cuestionaban la legitimidad de la venta de los recursos naturales a corporaciones transnacionales y la profunda corrupción que hacía parte de los acuerdos comerciales celebrados por el estado. En palabras de los protagonistas: "Todos esos políticos son corruptos. Ninguno se salva, pues ese es el mal de las altas esferas del gobierno". "Queremos que Banzer se vaya con sus ministros y todos esos políticos corruptos. Queremos justicia social. Queremos que nuestras vidas cambien" (Shultz, 2000). 


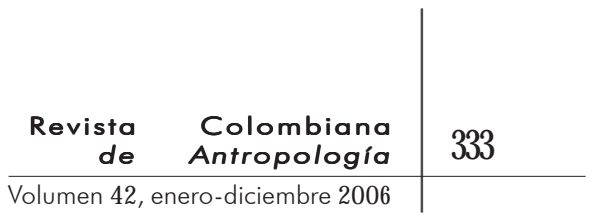

\section{El estado coqueto}

A LGUNOS AUTORES SOSTIENEN QUE LA GLOBALIZACIÓN DE LA PRODUCA ción e intercambio capitalistas se ha vuelto aún más autónoma de los controles políticos. Parte de esta tendencia es representada por Hardt y Negri (2000: xi-xii), para quienes la soberanía del estado desaparece, siendo transferida a unas entidades indefinidas, sin "rostro", de presencia espectral, "descentradas y deterritorializadoras". De acuerdo con estos autores, este hecho es lo que le da a las transnacionales gran libertad para actuar: la seguridad y la confianza de ser invisibles para el común de la gente a quienes "sirven", pero al mismo tiempo visibles jurídica y comercialmente frente al estado anfitrión. Sin embargo, como demuestra este artículo, la libertad de mercado no significa necesariamente relegar al estado de su posición central. De hecho, la gente es suficientemente consciente de esto y por medio del estado que logra imaginar y oponerse a las transnacionales. Mientras que la privatización se basa en la retórica de la desaparición del rol del estado, lo que se percibe efectivamente es una intervención mayor por parte del estado, especialmente en políticas del agua (Van der Zaag y Bolding, 2005). "El estado tiene que legislar en políticas públicas sobre recursos naturales como el agua; proteger dichos recursos; promover la conservación; y asegurar la equidad y la justicia social” (Iyer, 2003 114). La guerra del agua, más allá de haber sentado un precedente como una de las respuestas sociales más efectivas en contra de las políticas neoliberales y haber nutrido el debate sobre el carácter público o privado de un recurso natural, sin duda muestra a un estado que ejerce un importante rol en los procesos económicos globalizadores.

Es un hecho que para producir riqueza las transnacionales dependen de las mismas fronteras nacionales que transgreden y de las instituciones del estado (Comaroff y Comaroff, 2000; Krasner, n. d). El mercado no actúa en el vacío, y el estado no es sólo un objeto inerte en el que la economía impacta. Ciertamente, ningún mercado puede existir sin orden ni regulación política. Por tanto, si por libre mercado entendemos un mercado autónomo y espontáneo, libre de controles políticos, entonces no existe tal cosa llamada libre mercado. En una publicación posterior, Hardt y Negri (2004) afirman que los estados continúan ejerciendo muchas de sus funciones tradicionales, pero son transformados por el poder emergente global que ellos tien- 


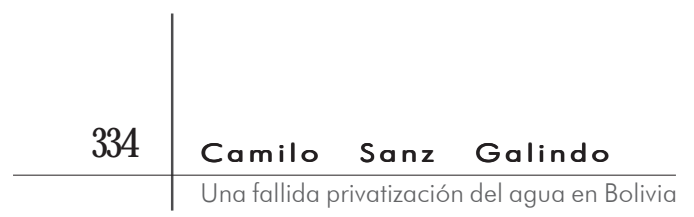

den a servir. El neoliberalismo, afirman, no es realmente un régimen de capital sin regulación, sino, por el contrario, una forma de regulación estatal que facilita los flujos globales de riqueza y ganancia del capital.

Emerge entonces una nueva clase de estado, cuya prioridad es crear un clima favorable para el capital extranjero; el estado mismo se convierte en un agente para la mercantilización del colectivo, al situarse en un escenario dominado por el mercado (Brenner, 1999), mientras se produce la dispersión simultánea de la autoridad pública y emergen múltiples formas de "gobierno privado indirecto" (Mbembe, 2001). Para estar seguros, Saskia Sassen (2002) afirma que los estados participan, con mucha frecuencia, en el establecimiento de los marcos fiscales y legales mediante los cuales la economía global se sostiene. De acuerdo con esta autora, las acciones del estado ya no se dirigen exclusivamente hacia los intereses nacionales, sino, por el contrario, hacia la estructura de poder global emergente. Desde esta perspectiva, sin duda, no habría contradicción entre el estado y la globalización.

Como parte de la adquisición, creación y conquista de mercados, la línea entre lo legal y lo ilegal, lo público y lo privado, es distorsionada por las actividades de personas ligadas a aquellos con poder y quienes, simultáneamente, operan desde la esfera privada. En general, los procedimientos necesarios para llevar a cabo privatizaciones -casi siempre de negocios del estado- y la gobernabilidad del agua se encuentran concentrados en las manos de "élites locales" y de aquellos cercanos a la cabeza del estado (Waalewijn et al., 2005). Eventualmente, delegar poderes ejecutivos en niveles más localizados puede hacer que los jefes locales capturen las nuevas plataformas creadas por el gobierno central y las usen para sus propios intereses (Mamdani, 1990, 1992). Los gobiernos deben, entonces, asegurar sus poderes reguladores a niveles locales de tal manera que se mantengan y respeten los derechos y deberes constitucionales, así como las obligaciones que trascienden fronteras. Sin embargo, en la práctica el logro de dichos objetivos se dificulta, justamente, debido a la relación ambigua entre estado y mercado. 


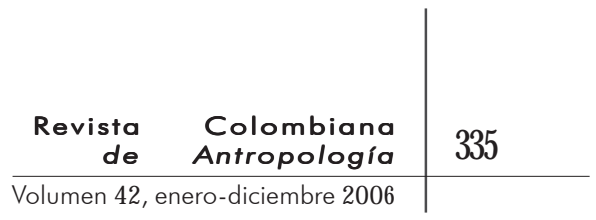

\section{Estado y mercado: unidad fundamental en la diferencia}

En 1999, después de privatizar muchas industrias, las mafias del gobierno y las transnacionales intentaron llevarse el agua. Ellos buscaban convertir este vital recurso en un negocio. Pero el agua es un bien público, una herencia natural de toda la humanidad. Todos sabemos esto. Gracias a las movilizaciones de la gente de Cochabamba, estas mafias vieron truncadas sus intenciones, y hasta ahora nadie posee el aire ni el agua bolivianos. Pero si las corporaciones y los políticos tuvieran otra oportunidad, no dudarían en usar todos los mecanismos para privatizarlos (Olivera, 2004: 27).

Durante las negociaciones entre el gobierno y Aguas del Tunari, descritas por observadores como "un proceso totalmente irregular y oscuro" (Albro, 2005, los términos del contrato se mantuvieron bajo gran confidencialidad, y la identidad de los inversionistas era un misterio. De hecho, algunas multinacionales insisten en que los documentos y la información concerniente al contrato deben mantenerse bajo la reserva más estricta, siendo inaccesibles no sólo para el ciudadano común, sino también para los mismos representantes del gobierno, incluso los involucrados en las negociaciones (Hall, 1999). Sólo después de que se firmara el contrato con Aguas del Tunari el gobierno accedió a hacer públicos los miembros del nuevo consorcio: International Water, Abengoa de España, y cuatro compañías bolivianas. International Water, que hace parte de las extensas propiedades de la estadounidense Bechtel Corporation, compró la mayoría de acciones del consorcio. Una de las compañías bolivianas pertenecía a Samuel Doria Medina, dueño de la franquicia de Burger King y prominente político de uno de los partidos gobernantes, el Movimiento de Izquierda Revolucionario.

La corrupción y la rapacidad son señaladas como modos de comportamiento político compartido por una pluralidad de actores a gran escala. Tal y como muchos bolivianos sospecharon en su momento, los intereses del gobierno dependían, en buena parte, de los que perseguía Aguas del Tunari (Olivera, 2004). Sin duda, se produce una simbiosis mediante la cual prácticas que son condenables moral, ética y legalmente, logran existir palmo a palmo con las prácticas cotidianas del estado. En esta sección voy a ocuparme de este fenómeno. 


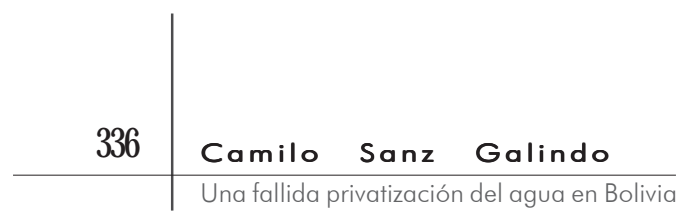

Propongo que, en vez de entender la corrupción como un aspecto disfuncional de las organizaciones del estado, debe ser vista, por el contrario, como un mecanismo absolutamente "natural" y por medio del cual el estado mismo se construye, mantiene y fortalece. Es un hecho que los fenómenos sociales interpretado por el sentido común como "corrupción” del estado o "decadencia política”, yacen en el corazón mismo de nuestro entendimiento del estado y dan luces sobre sus luchas sociales, su relativa indeterminación y, finalmente, su cultura moral (Bayart, 1993). Así las cosas, pretendo discutir que en Bolivia prácticas neoliberales como la privatización proporcionaron al país las condiciones necesarias para lograr el afianzamiento de las prácticas "subterráneas” y, así mismo, dieron gran libertad de movimiento a las transnacionales que operan allí. En otras palabras, el estado se confunde con el mercado y entra en una relación simbiótica con este. Las prácticas resultantes de esta hibridación produjeron el desvanecimiento gradual de la línea divisoria entre regulación e irregularidad, público y privado (Comaroff y Comaroff, n. d). En síntesis, se genera la hibridación del capital público y privado, en vez de producirse una simple relación de exclusión y competencia.

Durante las últimas décadas, algunos académicos han notado cómo las estructuras de las corporaciones y las entidades del estado se desarrollan muy de cerca unas de otras, hasta el punto en el que las firmas comerciales están, cada vez más, sólidamente insertadas en las instituciones públicas (Krasner, 1978; Bayart, 1993 Mbembe, 2000, 2001. No debería sorprendernos el hecho de que, en el transcurrir de sus carreras, los mismos individuos transiten con frecuencia, y sin esfuerzo, desde los altos cargos gubernamentales hasta puestos ejecutivos de las empresas privadas, y viceversa. En este sentido, el estado y los operadores privados actúan complementariamente, cuando no se confunden entre sí, cambiando sombreros según las circunstancias. El estado mismo asume diversas formas particulares y hace posible una amplia gama de combinaciones, no en el sentido de homogeneidad, sino de mantener juntos los diversos -y diferentes- elementos. De acuerdo con Bayart (1993), la capacidad que tiene el estado para sufrir esta metamorfosis y producir diversas combinaciones, es conocida como "rizoma" o el "estado rizomático". Al trabajar con base en este modelo teórico, pretendo consolidar mi visión del neoliberalismo y enmarcar más claramente la relación ambigua entre el estado y el mercado. Pero 


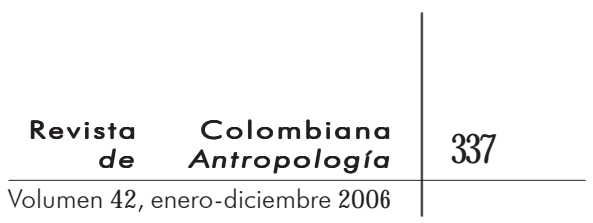

antes que nada, deberé retomar el modelo original de "rizoma" propuesto por Deleuze y Guattari (1987).

A diferencia de las estructuras en la forma de los árboles, los troncos y las hojas, para Deleuze y Guattari el rizoma es un sistema de raíces que se expande subterráneamente. Según los autores, "es un sistema descentrado, no jerárquico, sin significado y carente de una memoria general organizadora o control central, definido solamente por un constante flujo de estados" (Ibid.: 21). Este sistema asume muy diversas formas, "desde extensiones superficiales ramificadas en todas direcciones y encarnadas en bulbos y tubérculos". "El rizoma incluye lo mejor y lo peor" (Ibid.: 7). Es una dimensión paralela que existe en relación con un sistema "superior", es decir, con las formas "visibles". Dentro de esta lógica, vale recalcar que ni el sistema "superior" ni el "subterráneo" pueden existir independientemente uno del otro. Ambos existen y son objetivados en tanto logren mantener una relación íntima entre ellos. Esta relación hace que las raíces, los bulbos y los tubérculos sean parte intrínseca del tronco y las hojas; ambos sistemas forman el "árbol".

De esta manera, este tipo de conglomerados estructurales se produce mediante un proceso que convierte y asimila la diferencia. Esta es efectivamente la movida "rizomática": el tronco, las hojas y las raíces son siempre la "alteridad" necesaria y mediadora por conducto de la cual los dominios de la organización social, las categorías y las prácticas son actualizados como funcionales en un proceso de reconciliación para la realidad existente. Para decirlo de otra manera, todas las dualidades entre forma y contenido, valor de cambio y valor de uso, estado y mercado, sujeto y objeto, diferencia y contradicción, son "superadas".

Para obtener un esbozo aún más claro de la situación descrita, vale la pena recurrir al caso africano de la cuenca del Chad, ampliamente descrito como centro de contrabando, donde la "ilegalidad" y la "legalidad" existen en una relación simbiótica, nunca como centro de oposición frente al estado (Roitman, 2005). Tal y como argumenta Mbembe (2000, 2001, 2002), los elementos que a simple vista parecen obstáculos para el funcionamiento del estado pueden, eventualmente, terminar perteneciendo a este mismo. La relación de la estructura formal del estado con redes de concesiones informales, privilegios negociados cuidadosamente, relaciones políticas y personales se encuentran ampliamente reflejada en las entrevistas realizadas por Janet Roitman a policías 


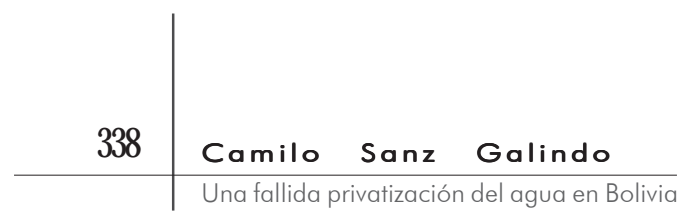

fronterizos y contrabandistas de gasolina. Para el primer grupo, el "pago" que reciben de los traficantes es una manera de complementar el sueldo modesto que ganan como servidores del estado, pero también una forma en la que el mismo estado se nutre y reproduce; para el caso del segundo grupo, es bien sabido que la viabilidad del contrabando depende de que existan prohibiciones y leyes que violar. Ambos, contrabandistas y policías, crean modos paralelos de enriquecimiento y establecen un simulacro de orden social.

Normalmente, los estados que han ido más lejos en el proceso de desregulación se caracterizan por la existencia de una estructura de poderes que rodea, y hasta controla, los principios oficiales del poder estatal. Los integrantes de esta estructura explotan para su propio beneficio empresas públicas e instituciones financieras, cuerpos reguladores, pero también abusan de la liberalización de las instituciones económicas al emplear mecanismos como la privatización, el fraude por medio del uso de intermediarios y las redes personalizadas (Bayart et al., 1999). Tal y como demuestra el caso boliviano, las privatizaciones y los ajustes estructurales fomentan el surgimiento de una economía basada en concesiones hechas a partir de monopolios lucrativos, contratos secretos, negocios y acuerdos privados, $\mathrm{y}$ privilegios en diferentes industrias como la minería del estaño, el gas y el transporte.

Lo que está ocurriendo es un proceso en el que las redes internacionales de traficantes, contrabandistas y negocios se fusionan con comerciantes locales y "tecnócratas", haciendo posible la consolidación de métodos de gobierno basados en altos niveles de corrupción (Mbembe, 2001). Usualmente, de acuerdo con Deleuze y Guattari, la única manera de acceder al rizoma es ser parte del mismo sistema, esto es, como ya he dicho, estar relacionado con las redes personales y la actividad contratista del estado. Es innegable que es más fácil hacerse rico desde una posición de poder que desde una de penuria y dependencia. "Yo serrucho, tú serruchas" era la premisa que conducía a la invención de modernidades particulares del estado que circunscriben las ganancias del "pastel nacional” (Bayart, 1993 87). Su relación con el estado es la que habilita a los actores para volverse ricos y figuras dominantes de la escena nacional. La relación entre detentar posiciones de poder dentro de los aparatos del estado y la adquisición de riqueza también se encuentra 


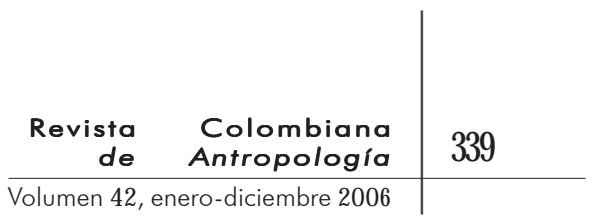

claramente relacionada con la jerarquía política. Entonces, los grupos poderosos se reservan para ellos, con completa impunidad y complicidad, la posibilidad de desobedecer sus propias reglas y leyes y crear un vasto sector económico que yace afuera de la ley.

En palabras de Deleuze y Guattari (1987), el rizoma se constituye como una variabilidad infinita de redes, cuyas ramificaciones subterráneas se unen a los puntos más dispersos y fangosos de la sociedad. Para entenderlo debemos esforzarnos por ir más allá de los nudos institucionales superficiales y, a cambio, internarnos en las profundidades de sus raíces para analizar los bulbos y los tubérculos desde donde extrae secretamente su alimento y existencia. Así pues, este rizoma está compuesto, por una parte, de redes sociales informales y el estado, y, por otra, del mercado, en el que la regulación económica se efectúa no tanto por la ley ni las reglas formales, como por el prestigio personal y la fortaleza de las relaciones privadas. En consecuencia, los procesos administrativos y las reglas legislativas o institucionales son solamente un canal, entre otros tantos, por medio del cual las autoridades públicas manejan los asuntos del país. Las relaciones personales, de naturaleza política o económica, ofrecen con frecuencia instrumentos mucho más efectivos de administración pública (Hibou, 1999).

Las partes involucradas en los acuerdos comerciales se ven obligadas a negociar en dos áreas a la vez. Según Hibou (1999. 96), "pareciera que las negociaciones oficiales fueran solamente una formalidad sin mayor contenido ni resultados concretos. Si el pago apropiado se da, las negociaciones paralelas serán las que den resultados”. Para Deleuze y Guattari (1987) esta situación habría significado, muy seguramente, la apropiación mutua de elementos del mercado y del estado; el estado es "deterritorializado", convirtiéndose en una pieza clave del mercado, pero al mismo tiempo, este ultimo "re-territorializa" al estado al desarrollar, dentro de sí, los marcos legales y políticos dictados por este mismo. Así pues, estado y mercado, como elementos heterogéneos, forman un rizoma dentro del cual ocurre una transformación palpable del mercado en estado y del estado en mercado. Ambos se interconectan y forman retransmisiones en un flujo de intensidades que dinamizan aún más la mencionada "deterritorialización”. Esta es la co-evolución de dos entidades que, según los neoliberales, poco tendrían en común. 


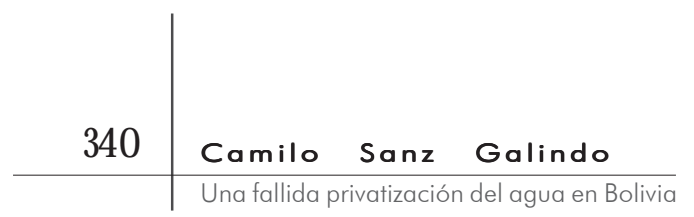

La corrupción en sus diferentes manifestaciones -mediante redes personales, contactos comerciales, acuerdos, contrataciones ilegales y oferta de sobornos-, reconcilia las organizaciones políticas y económicas que fueron pensadas erróneamente como incompatibles (Roitman, 2005 Escalante, 2000; Lomnitz, 2000; Bayart, 1993). Aparte del caso mencionado sobre el político boliviano y su relación con Aguas del Tunari, la historia de este país -como la colombiana- es absolutamente rica en estos fenómenos: el presidente Banzer, quien fue presidente dos veces: de 1971 a 1978, como dictador, y luego de 1997 a 2001 como presidente electo democráticamente, fue un reconocido dueño de grandes extensiones de tierra y ganado en la región de Santa Cruz. Durante su primer mandato fue reticente en adoptar las urgentes reformas agrarias que el país clamaba en aquella época; Gonzalo Sánchez de Lozada, dos veces presidente, de 1993a 1997, y luego de 2002 a 2003 cuando fue obligado a renunciar y dejar el país, era dueño de importantes minas de estaño, y como presidente implementó reformas neoliberales para privatizar la industria minera y vender los yacimientos a inversionistas extranjeros.

Parece claro que estamos discutiendo poderes del estado concentrados en manos de individuos o grupos, quienes se encuentran principalmente preocupados por ganar un mejor lugar desde donde obtener beneficios políticos y comerciales. El resultado es el debilitamiento de la línea divisoria entre el mercado y el estado (Mitchell, 1991, 1999) y el surgimiento de un gobierno paralelo (Mbembe, 2001) que no desafía al gobierno oficial o formal, sino que, por el contrario, se adapta a él para existir. Tal y como aseguran Comaroff y Comaroff (n. d), legalidad e ilegalidad, la presencia o ausencia de la ley, son las condiciones que permiten la existencia de cada una de estas mismas posibilidades. Precisamente así actúan los cleptócratas del siglo veintiuno, quienes, dentro de la dialéctica de "ley y (des)orden" planteada por los mencionados autores, cometen, por un lado, grandes robos y actos de corrupción organizados jurídicamente, promulgando legislaciones que autorizan actos de expropiación o redefinición de los espacios públicos y privados, mientras que, por el otro, violan flagrantemente la misma ley que en su momento crearon y supieron defender. 


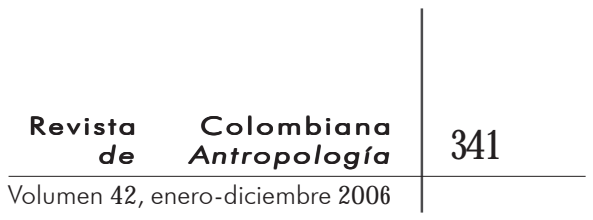

\section{Comentarios finales}

\section{Hacia un replanteamiento de lo público y lo privado}

D E FORMA SORPRESIVA, EN 2004 EL FMI Y EL BANCO MundIAL PUBLIcaron un documento en el que reconocen que no tienen la evidencia suficiente para apoyar el supuesto general de la eficiencia superior del sector privado. El documento plantea que: "No puede darse por sentado que la privatización sea más eficiente que la inversión pública y el suministro estatal de servicios", y respalda esto al hacer referencia a los argumentos y evidencia existentes: "Mucho de lo que se ha dicho sobre las privatizaciones se basa en la relativa eficiencia del sector privado. Mientras que existe una extensa literatura sobre este tema, la teoría es ambigua y la evidencia empírica se encuentra mezclada”. En julio de 2003, The Wall Street Journal publicó un artículo titulado "The World Bank as privatization agnostic" ("El Banco Mundial como agnóstico de la privatización”), en el que se citan declaraciones de oficiales de este organismo sobre la reevaluación de sus políticas de privatización: "Indudablemente se está dando mucho de meditación y arrepentimiento", dice Michael Klein, el vicepresidente para el desarrollo del sector privado del Banco. Y el artículo anuncia que "Los oficiales del Banco Mundial han decidido que ahora no importa tanto si la infraestructura se encuentra en manos privadas o públicas". Evidencia empírica proveniente de varias fuentes señala que no existe una diferencia sistemática en eficiencia entre operadores públicos y privados (Hall, 2005). Si este fuera el caso, en el que ni lo privado ni lo público se encuentran tan opuestos como se creía, ¿qué sucede entonces con la utilidad de dichas categorías? ¿Cómo se genera el efecto que hace que ciertos aspectos de lo que ocurre pertenezcan a lo privado y otros a lo público? ¿Acaso lo privado y lo público, como dominios separados, se constituyen meramente en un simple espejismo? O, por el contrario, ¿debemos continuar insistiendo en que ambos dominios sean diferentes y separados el uno del otro?

Esta evidencia apoya mi propuesta inicial sobre el debilitamiento y el carácter borroso de los marcadores de certeza, y contribuye de manera importante a socavar la separación común entre mercado y estado. Sin duda, la frontera mercado/ 


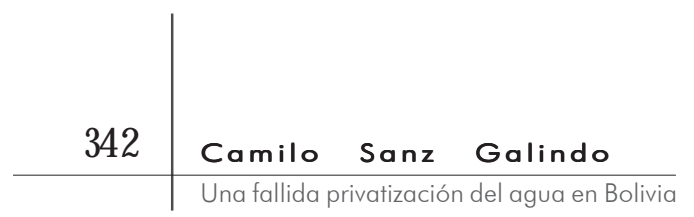

estado es escurridiza, porosa, móvil y está compuesta de innumerables divisiones internas. Necesitamos llevar nuestro análisis al punto en donde estas divisiones se hagan visibles y evidencien la naturaleza fluctuante entre los dominios, evitando, en consecuencia, establecer correlaciones simplistas entre ellos (Mitchell, 1991, 1999). En vez de ser seducidos u obstaculizados por los dominios entendidos como público o privado, comenta Bhattacharjee (2006), necesitamos estar vigilantes y ser concientes de su carácter de "espejismo". Sólo al entender sus construcciones y consecuencias políticas podremos aspirar a modificarlas.

El caso del agua permite ver más claramente la manera como estos dominios entran en conflicto y renegociación entre ellos. Con el fundamentalismo del libre mercado, lo público y lo privado es reformulado y el caos organizado del gobierno produce la desintegración gradual de la frontera entre regulación e irregularidad (Roitman, 2005), público y privado. Esta desintegración, así como la mercantilización de un derecho humano, es resultado del ambiguo proceso legislativo que enmarca las actividades comerciales en países como Bolivia.

Desde la perspectiva "rizomática", el estado se encuentra constituido por una red de relaciones de poder permeante que no está limitada solamente por los aparatos estatales convencionales. Tal y como he tratado de demostrar, el estado existe en tanto establezca una relación simbiótica con prácticas y actividades entendidas comúnmente como opuestas a él mismo. El estado y el mercado no son dos espacios distintos ni mutuamente limitativos, sino parte de una misma configuración. Se trata, por tanto, no de cuestionarnos si el estado es débil o fuerte o si las fuerzas políticas intervienen en la economía. Por el contrario, como explican Hardt y Negri (2004), se trata sólo de preguntarnos cómo el estado y otras fuerzas políticas intervienen y cómo generan una relación de convivencia entre elementos aparentemente contradictorios y no armoniosos; robo y corrupción no van en contra del estado, sino, por el contrario, dependen de él, mientras que, por otro lado, el estado depende de estas prácticas. Esta es, como diría Walter Benjamin (1978), la confusión primera entre ley y caos sobre la cual todos los estados se encuentran fundados. 


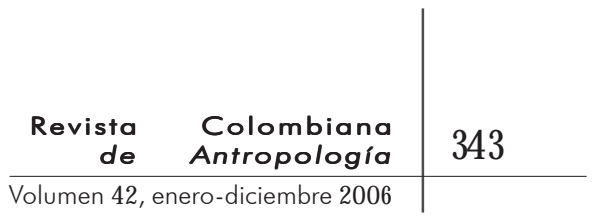

\section{Bibliografía}

Agamben, Giongio. 2005 State of Exception. The University of Chicago Press. Chicago.

Albro, Roberto. 2005 “'The water is ours, Carajo': Deep citizenship in Bolivia's water war”. En June Nash (ed.). Social movements: An anthropological reader. Malden. Blackwell Publisher.

Bayart, Jean-François. 1993 The State in Africa: Politics of the Belly. Longman. Nueva York.

Bayart, Jean-François, Stephen Ellis, Béatrice Hibou. 1999. The criminalization of the State in Africa. Indiana University Press/ James Currey in association with the International African Institute. Bloomington/Oxford.

Benjamin, Walter. 1978 "Critique of violence". En Reflections: Essays, aphorisms, autobiographical writings. Schocken Books. Nueva York.

BhattacharjeE, Anannya. 1996. “Thepublic/private mirage: Mapping homes and undomesticating violence work in the south Asian immigrant communit”. En Akhil Gupta (ed.). The anthropology of the State. Blackwell Publishing. Massachusetts.

BRENNER, NEIL. 1999. " Beyond state-centrism? Space, territoriality, and geographical scale in globalization studies". Theory and Society. 28.

Cherian, John. 2003 “The Bolivian uprising”. Frontline. 20 (23). 8-21 de noviembre. India.

Comaroff, Jean y John Comaroff. n. d. Law and disorder in the Post Colony: An introduction.

_2000. "Millenial capitalism: First thoughts on a second coming". Public Culture. D (2).

Coronil, Fernando. 1997. Magical State: Nature, money and modernity in Venezuela. The University of Chicago Press. Chicago.

Deleuze, Gilles y Felix Guattari. 1987. A thousands plateaus: Capitalism and schizophrenia. University of Minnesota Press. Minneapolis.

DerRida, Jacques. 2002. "Force of Law". En Gil Anidjar (ed.). Acts of Religion. Routledge. Nueva York.

Escalante, Fernando. 2000. "Piedra de escándalo. Apuntes sobre el significado político". En Claudio Lomnitz (ed.). Vicios públicos, virtudes privadas: la corrupción en México. Ciesas. México.

Finger, Matthias y Jeremy Allouche. 2001 Water privatization: Transnational corporations and the re-regulation of the water industry. Spon Press. Nueva York. 
FinNegan, Wildiam. 2002. "Leasing the rain". The New Yorker. 8 de abril.

GiLl, LesLIE. 2000. Teetering on the Rim, global restructuring, daily life, and the Armed retreat of the Bolivian State. Columbia University Press. Nueva York.

Goldman, Michael. 2005 Imperial nature: The World Bank and struggles for social justice in the age of globalization. Yale University Press. New Heaven.

Hall, David. 2006. "Pipe dreams: The failure of the private sector to invest in water services in developing countries". http:// www.psiru.org/reports/2006-03W-investment.pdf (última consulta 25 de julio de 2006).

2005 "Public resistance to privatization in water and energy". En Development in Practice. 15 (3 y 4). http:// www.psiru.org/reports/200506- W-E-resist.pdf (última consulta 25 de julio de 2006.

2004. "Making water privatization illegal: New laws in Netherlands and Uruguay". http://www.psiru.org/reports/200411-w-crim.doc (última consulta 25 de julio 2006).

_. 1999. "Contracts, concessions and corruption in the water sector". United Nations Centre for Human Settlement (Habitat). http://www.unhabitat.org/HD/hdv6n3/contracts.htm (última consulta 23 de julio).

Hardt, Michael y Antonio Negri. 2004. Multitude: War and democracy in the age of Empire. The Penguin Press. Nueva York.

. 2000. Empire. Harvard University Press. Cambridge.

HaRvey, David. 2005 A brief history of neoliberalism. Oxford University Press. Oxford.

- 2003 The new imperialism. Oxford University Press. Oxford.

Hibou, Béatrice. 1999. "The social capital of the State as an agent of deception, or the Ruses of economic intelligence”. En Jean-François Bayart, Stephen Ellis y Béatrice Hibou (eds.). The criminalization of the State in Africa. Indiana University Press. Bloomington.

International Monetary Fund. 2004. "Public-private partnerships March 12". http://www.imf.org/external/np/fad/2004/pifp/eng/ 031204.htm (última consulta 26 de julio de 2006).

Iyer, Ramaswamy. 2003 Water perspectives, issues, concerns. Sage Publications. Nueva Delhi.

KRASNer, Stephen. 1978. Defending the national interests: Raw materials investment and the U.S foreign policy. Princeton University Press. Princeton. 


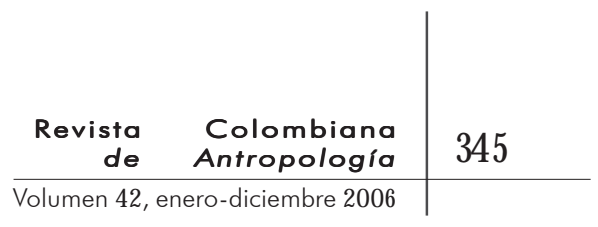

n. d. Globalization, power and authority.

Lefebvre, Henri. 1991 The production of space. Blackwell. Cambridge.

Lefort, Claude. 1988. Democracy and political theory. Polity Press. Oxford.

LOMNITZ, Claudio. 2000. "Ritual, rumor y corrupción en la conformación de los sentimientos de la Nación”. En Claudio Lomnitz (ed.). Vicios públicos, virtudes privadas: la corrupción en México. Ciesas. México.

. 1982. Evolución de una sociedad rural. Fondo de Cultura Económica. México.

MacKinnon, Catharine. 1989. Toward a feminist theory of practice. Harvard University Press. Cambridge.

Mamdani, Mahmood. 1992. "Africa: Democratic theory and democratic struggles”. Dissent. Summer.

- 1990. "State and civil society in contemporary Africa". Africa Development. 15(34).

Mвемве, Асншце. 2002. "African modes of self-writing”. Public Culture. 14. 2001 On the Postcolony. University of California Press. Berkeley.

2000. "At the edge of the world: Boundaries, territoriality, and sovereignty in Africa”. Public Culture. $\mathbb{2}$ (1).

Mitchell, Timothy. 1999. "Society, economy and the State effect”. En Aradhana Sharma y Akhil Gupta (eds.). The anthropology of the state: A reader. Blackwell Publishing. Nueva York.

—. 1991 "The limits of the State: Beyond statist approaches and their critics”. American Political Science Review. 85(1).

Nash, June. 1979. We eat the mines and the mines eat us: Dependency and exploitation in Bolivian tin mines. Columbia University Press. Nueva York.

Olivera, Óscar. 2004. Cochabamba. Water war in Bolivia. South End Press. Massachusetts.

Petras, James. 2004. “Bolivia: Between colonization and revolution”. http:/www.canadiandimension.mb.ca/v38/v38_lip.htm (última consulta 2 de noviembre de 2004).

Pietz, William. 1993 "Fetishism and materialism: The limits of theory in Marx". En Emily Apter y William Pietz (eds.). Fetishism as cultural discourse. Cornell University Press. Ithaca.

Portes, Alejandro, Hoffman, Kelly. 2003 "Latin American class structures: Their composition and change during the neoliberal era”. Latin America Research Review. 38 (1). 
Postero, NAncy. 2005 "Indigenous responses to neoliberalism: A look at the Bolivian uprising of 2003'. Political and Legal Anthropology Review. 28 (1).

Poulantzas, Nicos. 1978. State, power, socialism. Verso. Londres.

Roitman, Janet. 2005 Fiscal disobedience. Princeton University Press. Princeton.

Rosdolsky, Roman. 1977. The making of Marx's Capital. Pluto Press. Londres.

SASSEN, SASKia. 2002. “The State and globalization”. En Rodney Hall $\mathrm{y}$ Thomas Biersteker (eds.). The emergence of private authority in global governance. Cambridge University Press. Cambridge.

Shultz, Jim. 2000. "Bolivia's war over water resources”. http:// www.democracyctr.org/waterwar (última consulta 25de julio de 2006).

Thomas, Paul. 1994. Alien Politics: Marxist state theory retrieved. Routledge. Nueva York.

VAn der ZaAg, Pieter y Alex Bolding. 2005 "Water governance in the Pungwe river basin: Institutional limits to the upscaling of hydraulic infrastructure". Documento preparado para la Transboundary water governance: Lessons learned in South Africa, of the 6th Open Meeting of the Human dimensions of global environmental change research community, $\mathbf{2}$ de octubre 2005 University of Bonn.

WAalewijn, P., P. Wester y K. van StraAten. 2005 “Transforming river basin management in South Africa; lessons from the Lower Komati River". Water International. 30 (2). 